\title{
A clinical and molecular study of artesunate + sulphadoxine-pyrimethamine in three districts of central and eastern India
}

Prakriti Srivastava ${ }^{1 *}$, Jagnyeswar Ratha ${ }^{2}$, Naman K Shah ${ }^{1}$, Neelima Mishra', Anupkumar R Anvikar ${ }^{1}$, Surya K Sharma ${ }^{1}$, Manoj $\mathrm{K} \mathrm{Das}^{3}$, Bina Srivastava ${ }^{1}$ and Neena Valecha ${ }^{1}$

\begin{abstract}
Background: Artesunate + sulphadoxine-pyrimethamine (AS + SP) is recommended throughout India as the first-line treatment for uncomplicated falciparum malaria. Due to the presence of several eco-epidemiological zones of malaria and variable drug pressure, it is necessary to evaluate the efficacy of this combination in different regions of India. The objective of this study was to use clinical and molecular methods to monitor the efficacy of AS + SP in three diverse sites.

Methods: The study was undertaken in three high endemic sites of central and eastern India. Patients with uncomplicated falciparum malaria were enrolled and followed for 28 days. Molecular genotyping was conducted for merozoite surface protein ( $m s p 1$ and msp2) to differentiate between re-infection and recrudescence and for the dhfr and dhps genes to monitor antifolate drug resistance.

Results: In all, 149 patients were enrolled at the three sites. The crude cure rates were 95.9\%, 100\%, and 100\% in Ranchi, Keonjhar, and West Garo Hills respectively. PCR-corrected cure rates were 100\% at all sites. In dhfr, 27\% of isolates had triple mutations, while $46 \%$ isolates were double-mutants. The most prevalent mutation was $\mathrm{S108N}$ followed by C59R. $164 \mathrm{~L}$ mutation was observed in 43/126 (34\%) isolates. In dhps, most (76\%) of the isolates were wild-type. Only $2.5 \%$ (2/80) isolates showed double mutation. dhfr-dhps two locus mutation were observed in 16\% (13/80) isolates. Parasite clearance time was not related with antifolate mutations.

Conclusions: AS + SP combination therapy remained effective against falciparum malaria despite common mutations promoting resistance to antifolate drugs. Although the prevalence of double and triple mutations in dhfr was high, the prevalence of dhfr-dhps two locus mutations were low. Even isolates with dhfr triple and dhfr-dhps two locus mutations achieved adequate clinical and parasitological response.
\end{abstract}

Keywords: Artesunate + sulphadoxine-pyrimethamine, Plasmodium falciparum, Dihydrofolate reductase, Dihydropteroate synthetase, Falciparum malaria

\section{Background}

Anti-malarial drug resistance has been a major obstacle in the fight against malaria and has been documented globally in Plasmodium falciparum. In India, chloroquine (CQ) resistance was first reported in Assam in 1973 [1] and thereafter several reports of resistance were confirmed from all over India [2-6]. Sulphadoxine-pyrimethamine

\footnotetext{
* Correspondence: srivastavaprakriti@rediffmail.com

${ }^{1}$ National Institute of Malaria Research, Sector 8, Dwarka, New Delhi 110077, India

Full list of author information is available at the end of the article
}

(SP) became the alternative to CQ for the treatment and control of uncomplicated malaria. It was effective, affordable and easy to comply with, but in course of time the accumulations of mutations in parasite genes coding for two enzymes dihydrofolate reductase (DHFR) and dihydropteroate synthetase (DHPS) led to SP resistance in certain sites, mostly in north-east India [7]. In 2001, the World Health Organization (WHO) recommended the use of artemisinin based combinations therapy (ACT), in which a long-acting partner is added to artemisinin to make it more effective, as first-line treatment for uncomplicated

\section{Biomed Central}


falciparum malaria [8]. Since 2005, most malaria-endemic countries adopted ACT. In 2005, AS + SP was introduced in the National Drug Policy for malaria in India in selected areas, and in 2010 it became the universal first-line drug for falciparum malaria. With the replacement of monotherapy by ACT, it is important to understand the relationship between molecular markers, parasite resistance and treatment failure.

Several challenges exist in understanding this correlation since molecular markers for artemisinin resistance have not been established. These markers however, are well established for SP. Sulphadoxine acts as competitive inhibitor in folate biosynthetic pathway of parasite by inhibiting the enzyme DHPS [9]. Pyrimethamine inhibits the DHFR enzyme of $P$. falciparum, also a component of the folate-biosynthetic pathway. Mutations in some of the key amino acids of this enzyme lead to reduced binding affinity with the drug, leading to resistance [10]. In the AS + SP combination, AS rapidly clears parasitaemia. SP kills the remaining parasites, since it has a long half-life in blood. Thus, for clinical and parasitological treatment outcomes, early treatment failure (ETF) is more likely associated with AS failure and late treatment failure (LTF) with SP failure. The determination of parasite density on day 0 and the proportion of patients positive on day 3 could thus be a key indicator for the in vivo susceptibility of artemisinin [11].

Since pre-existing resistance to SP exists in India, especially along the border with Myanmar where reduced artemisinin sensitivity has been reported, it is important to monitor both in vivo and in vitro responses to this combination. Therefore, the objective of the present study was to: 1) measure the in vivo efficacy of AS + SP including treatment failure and parasite clearance; 2) examine molecular markers for SP to understand the mutation pattern; and, 3) correlate molecular marker results with clinical outcomes.

\section{Methods}

This was a single arm prospective study carried out from 2007 to 2010 (Aug-Oct 2007 in Ranchi, Sep-Nov 2007 in Keonjhar and June-Oct 2010 in West Garo Hills) to evaluate the parasitological and clinical response to directly observed treatment for uncomplicated falciparum malaria [12].

\section{Study sites}

The study was carried out at three sites (Figure 1). Ranchi (Jharkhand): Jharkhand contributes to $7 \%$ of the two million reported cases of malaria in India. The study district Ranchi is the capital of Jharkhand and is highly endemic for malaria with an average elevation $629 \mathrm{~m}$ above sea level. Ranchi has a hilly topography with dense tropical forests. The main vector of malaria in
Ranchi is Anopheles fluviatilis and predominant tribes living there are Oram and Munda. Keonjhar (Odisha). In India, Odisha state contributes to $40 \%$ of reported $P$. falciparum cases. The climate of the study district is hot in summer with high humidity. The district is covered by $30 \%$ of forest of the total geographical area. Main vector of malaria is An. fluviatilis. There are 16 tribal populations in Keonjhar with the Oram and Munda as predominant tribes. West Garo Hills (Meghalaya): $P$. falciparum-related deaths are routinely reported annually from West Garo Hills district, located at the western most part of Meghalaya. There is heavy rainfall during May to September with a seasonal peak from May to July. The main vector of malaria is Anopheles minimus [13]. The Khasis are the largest group of tribes, followed by the Garos. Partial data from this study site was already published [14]. However detailed clinical and molecular data are presented in this paper.

\section{Enrolment}

All patients reporting to a local clinic with complaint of fever were examined for presence of parasites in the blood smear. The demographic information (age, gender, body temperature, body weight) were recorded. Peripheral smear was examined and those positive for $P$. falciparum were enrolled. Informed consent was obtained and case record form was completed for each patient.

\section{Inclusion and exclusion}

Patients aged above six months with mono-infection with P. falciparum, with parasitaemia of 1,000 to $100,000 / \mu \mathrm{l}$, axillary temperature $\geq 37.5^{\circ} \mathrm{C}$ or history of fever during previous 24 hours and agreeing to follow-up visits, were included in study. Patients with presence of one or more general danger signs or any sign of severe malaria, presence of mixed infection, severe malnutrition, febrile conditions caused by diseases other than malaria, contra-indications related to anti-malarial drugs used, and pregnancy, were excluded from this study.

\section{Treatment}

AS was given at a target dose of $4 \mathrm{mg} / \mathrm{kg}$ daily for three days; SP were given as a single dose equivalent to 25/ $1.25 \mathrm{mg} / \mathrm{kg}$ (IPCA Laboratories Ltd, Mumbai). Agewise dosing was followed rather than weightwise [15]. Patients were observed for $30 \mathrm{~min}$ and if they vomited during this period, the first dose was repeated.

\section{Follow-up}

Clinical (temperature, vital symptoms, physical parameters) and parasitological (thick and thin slide) assessment were done on days $0,1,2,3$ and 7 and then weekly until day 28 . However, patients were advised to return on any day during follow-up if symptoms existed. For defaulters, 


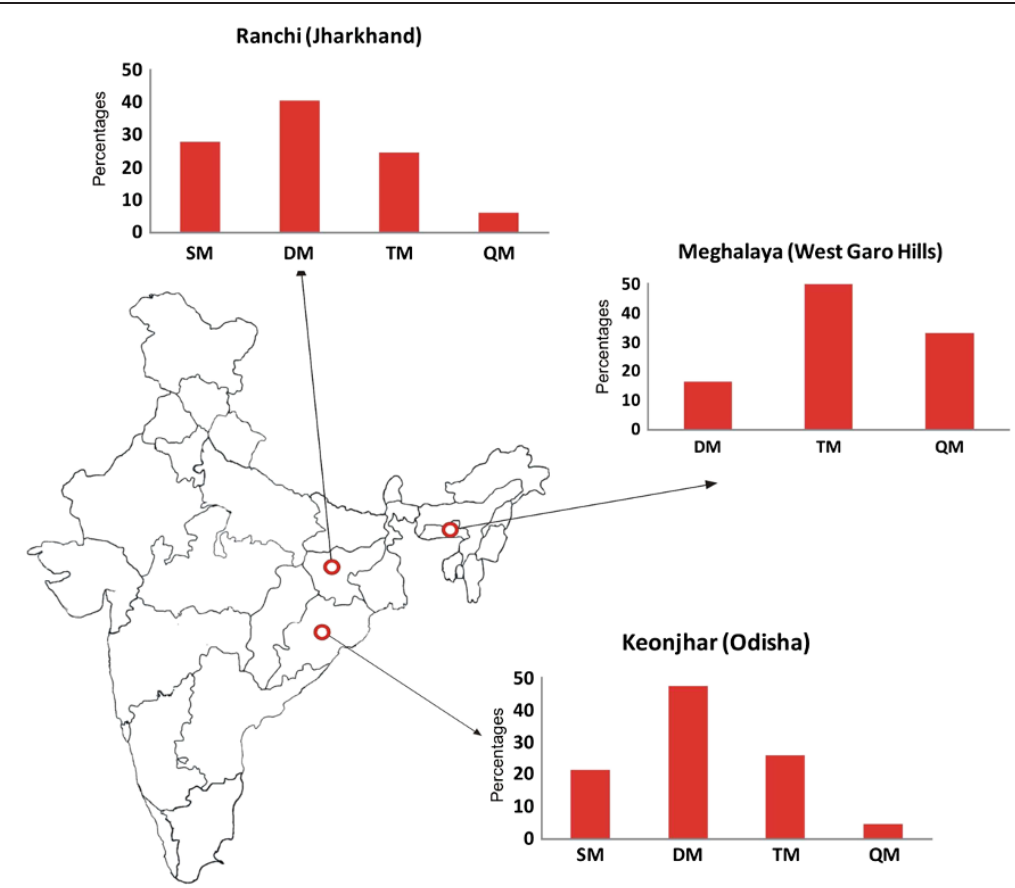

Figure 1 Selected study sites for AS + SP therapeutic efficacy studies, Keonjhar (Odisha), Ranchi (Jharkhand) and West Garo Hills (Meghalaya) and total mutations in dhfr and dhps gene, 2007 and 2010. Abbreviations: SM, single mutation, DM, double mutation, TM, triple mutation, QM, quadruple mutation.

follow-up was done by visiting the patient at their home or place of work. Patients were advised to use personal protection measures to prevent re-infection.

\section{Microscopy}

Thick and thin blood smears were examined for presence of parasite. Thick blood films were stained with Giemsa and parasite density determined by counting parasites against 200 white blood cells (WBC) and assuming WBC count to be $8,000 / \mu \mathrm{l}$. The parasite clearance time (PCT) was determined based on a daily blood smear as per the WHO protocol for therapeutic efficacy studies. Finger prick blood samples were collected on Whatman $3 \mathrm{~mm}$ filter papers on admission and on the day of re-appearance of parasites after complete anti-malarial treatment during follow-up and unscheduled day.

\section{Molecular analysis}

DNA was isolated from dried blood spot using DNA isolation kit according to manufacturer's instructions (Qiagen, Valencia, CA, USA). To distinguish re-infection and recrudescence, parasite genotyping for polymorphic loci, merozoite surface proteins ( $m s p 1$ and $m s p 2$ ) were conducted according to the published method [16]. Mutation specific PCR were conducted to amplify dhfr and dhps gene according to method described earlier [17]. The $d h f r$ fragment of 720 base pair was amplified first and then mutation specific PCR were carried out for codon 16,
51, 59, 108 and 164. In dhps, primary PCR were carried out to obtain a PCR product of $1.33 \mathrm{~kb}$. Nested PCR were performed using two flanking and seven mutation-specific primers to detect point mutations at codon 436, 437, 540, 581 and 613. Molecular markers were analyzed in all D0 samples to get data of the baseline antifolate mutations regardless of follow-up and clinical outcomes.

\section{Classification of outcomes}

Treatment outcomes were classified as early treatment failure (ETF), late clinical failure (LCF), late parasitological failure (LPF), adequate clinical and parasitological response (ACPR) on the basis of an assessment of the parasitological and clinical outcome of anti-malarial treatment according to the latest WHO guidelines [18].

\section{Data analysis}

Computer-based applications prepared by WHO for data management and analysis were used (software package developed by WHO's Global Malaria Programme for evaluating therapeutic efficacy). Data were entered into WHO software for Kaplan-Meier analysis for calculating cure rates. Results were expressed as the cumulative success rate and the proportion of adequate clinical and parasitological response (ACPR) before and after adjustment by PCR. The primary endpoint of the study was the per protocol (PP)-PCR corrected cure rate. The secondary endpoints included the parasite clearance time (PCT), 
fever clearance time, percent patients without gametocytes on day 28, and proportion of patients with ETF, LTF and LPF. The sum of $d h f r$ and dhps mutations were defined as the total number of antifolate mutations. Fisher's exact test was used to find association between antifolate mutations and parasite clearance.

\section{Sample size}

The study was designed according to WHO therapeutic efficacy protocol which recommends a minimum of 50 patients in a site for appropriate precision (5\%) to detect an unknown treatment failure rate with $95 \%$ confidence. We aimed to recruit approximately 70 patients in each site in case of loss to follow-up.

\section{Ethics}

The study was approved by Institutional Ethical Committee of National Institute of Malaria Research (NIMR). Patients were included in the study only if they or their parents or guardians gave informed consent. All information on patients was kept confidential.

\section{Results}

\section{In vivo efficacy of $\mathrm{AS}+\mathrm{SP}$}

A total of 149 patients were enrolled during 2007-2010 at three sites. Most patients were below 15 years of age

Table 1 Demographic and clinical characteristics of patients enrolled for AS + SP therapeutic efficacy studies, central and eastern India, 2007 and 2010

\begin{tabular}{|c|c|c|c|c|}
\hline $\begin{array}{l}\text { Keonjhar } \\
(\mathrm{N}=71)\end{array}$ & & & & $\begin{array}{l}\text { aro } \\
=25)\end{array}$ \\
\hline$\%$ & $n$ & $\%$ & $n$ & $\%$ \\
\hline
\end{tabular}

\begin{tabular}{|c|c|c|c|c|c|c|}
\hline \multicolumn{7}{|l|}{ Gender } \\
\hline Male & 31 & 44 & 22 & 42 & 15 & 60 \\
\hline Female & 40 & 56 & 31 & 58 & 10 & 40 \\
\hline \multicolumn{7}{|l|}{ Age groups } \\
\hline$<5$ & 31 & 44 & 12 & 22 & 7 & 28 \\
\hline $5-14$ & 25 & 35 & 19 & 36 & 14 & 56 \\
\hline$\geq 15$ & 15 & 21 & 22 & 42 & 4 & 16 \\
\hline \multicolumn{7}{|l|}{ Parasitaemia/ $\mu \mathrm{L}$ on day 0} \\
\hline$<5000$ & 27 & 38 & 8 & 15 & 12 & 48 \\
\hline $5000-50000$ & 29 & 41 & 34 & 64 & 10 & 40 \\
\hline$>50000$ & 15 & 21 & 11 & 21 & 3 & 12 \\
\hline \multicolumn{7}{|l|}{ Parasite clearance time } \\
\hline$<24$ hours & 46 & 65 & 48 & 90 & 22 & 98 \\
\hline $24-48$ & 23 & 32 & 5 & 10 & 3 & 2 \\
\hline$>48$ & 2 & 3 & & & & \\
\hline $\begin{array}{l}\text { Fever on day } \mathbf{0} \\
\text { (auxiliary temperature) } \geq 37.5^{\circ} \mathrm{C}\end{array}$ & 71 & 100 & 45 & 85 & 8 & 32 \\
\hline$\leq 37.5^{\circ} \mathrm{C}$ & 0 & 0 & 8 & 15 & 17 & 68 \\
\hline
\end{tabular}

Abbreviations: $N$, total number of patients enrolled; $n$, out of total enrolled. with fever on enrolment and parasitaemia between 5,000$50,000 / \mu$ l blood (Table 1). Out of 149 patients, four (3\%) were lost to follow-up and five (3\%) were withdrawals (four protocol violations in inclusion and one with Plasmodium vivax infection). There were two treatment failures on day 26 and 27 from Ranchi. No clinical or parasitological failures were reported from other sites (Figure 2).

The parasite clearance was rapid at all sites and complete clearance of parasitaemia within 48 hours of administration of drug were observed in 97\% (69/71) in Keonjhar, 100\% (53/53) in Ranchi and (25/25) West Garo Hills (Table 1). Proportion of patients with gametocytes at enrolment was $13 \%(9 / 71), 30 \%(16 / 53)$ and $12 \%(3 / 25)$ respectively in Keonjhar, Ranchi and West Garo Hills. Gametocytes were detected in only one patient on day 28 from West Garo Hills.

Out of two cases of treatment failure, one had temperature $38.5^{\circ} \mathrm{C}$ and $9 \%$ of day 0 parasitaemia on day 26 and classed as LCF. Another was classed as LPF as he had temperature $36.8^{\circ} \mathrm{C}$ and $21 \%$ of day 0 parasitaemia on day 28. Molecular genotyping for $m s p 1$ and $m s p 2$ of failure samples indicate multiple infections and classified as a re-infection. PP-PCR-uncorrected cure rates were 95.9\% (95\% CI: 86, 99.5), 100\% (95\% CI: 94.6, 100), and $100 \%$ (95\% CI: 86.3, 100) respectively at Ranchi, Keonjhar and West Garo Hills. After PCR-correction, cure rates were $100 \%$ at all sites.

\section{Molecular analysis of dhfr and dhps gene}

All isolates were analysed for dhfr mutations encoding pyrimethamine resistance and dhps mutations associated with sulphadoxine resistance (Table 2). In dhfr, 136 (91\%) isolates were successfully amplified. The S108N mutation was the most common and found in all amplified samples. Seventy-one percent of the samples were mutant at amino acid position C59R; I164L mutation was observed in 34\% of isolates. In $d h f r$, double mutants ( $1108 \mathbf{N}+\mathrm{C} 59 \mathbf{R}$ or I164L) were the most common in all three sites: Ranchi $(47 \%, \mathrm{n}=22 / 47)$ and Keonjhar $(49 \%, \mathrm{n}=27 / 55)$ and West Garo Hills $(17 \%, \mathrm{n}=3 / 18)$. Other than double mutations, the triple mutant C59R + S108N + I164L were also detected in all sites but its prevalence was highest in West Garo Hills $(83 \%, \mathrm{n}=15 / 18)$ followed by Ranchi $(28 \%$, $\mathrm{n}=13 / 47)$ and Keonjhar $(18 \%, \mathrm{n}=10 / 55)$. Single mutation S108N were observed in Keonjhar $(33 \%, \mathrm{n}=18 / 55)$ and Ranchi (26\%, $\mathrm{n}=12 / 47)$ only.

In dhps, out of 149 collected isolates, 88 (59\%) were successfully amplified. Mutations were found in 19\% ( $\mathrm{n}=17 / 88$ ) of the samples. A single mutation at amino acid position 581 was observed in $8 \%(n=7 / 88)$ and at amino acid position 540 was present in $6 \%(n=5 / 88)$ of isolates. Double mutations at position 540 and 581 were observed in $1 \%(n=1 / 88)$ of isolates. 


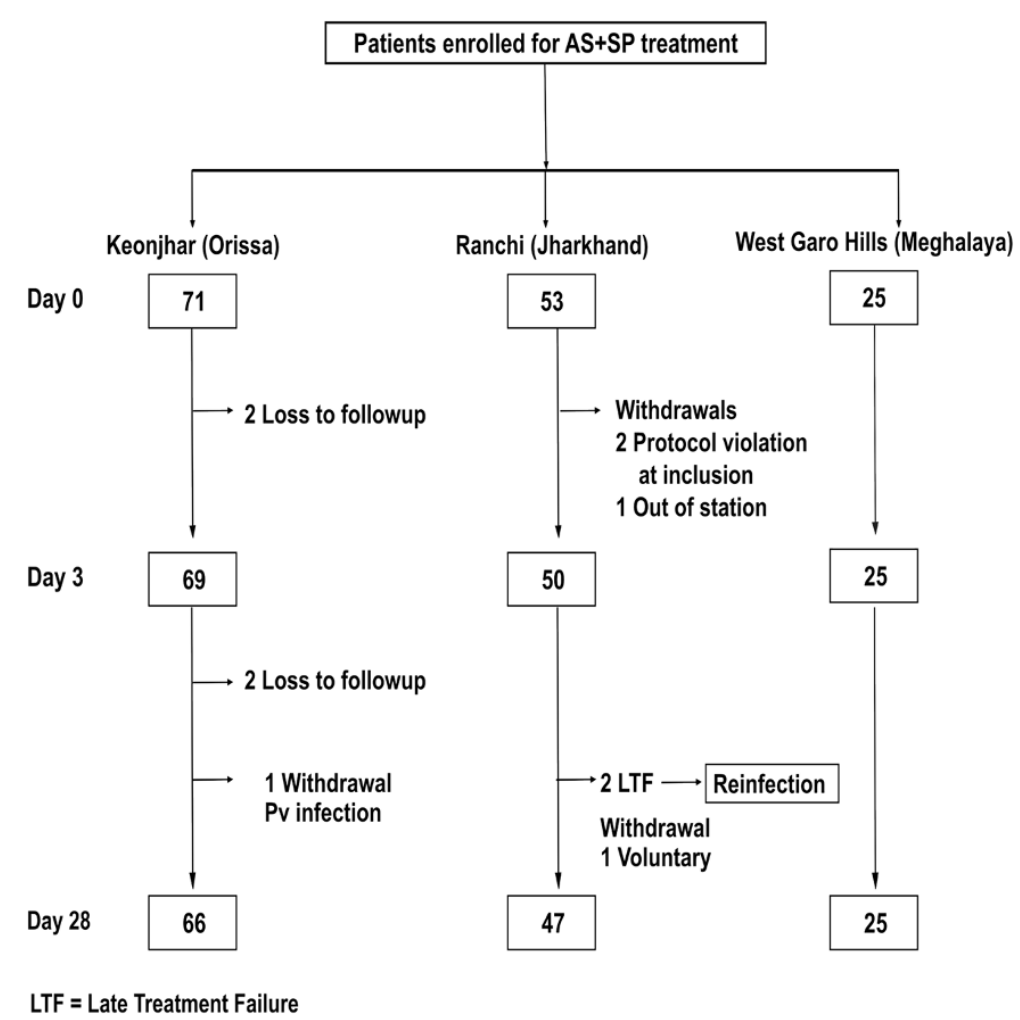

Figure 2 Flow chart of patients enrolled for AS + SP treatment at Keonjhar (Odisha), Ranchi (Jharkhand) and West Garo Hills (Meghalaya), India, 2007 and 2010. Abbreviations: PV, Plasmodium vivax; LTF, late treatment failure.

Considering dhfr and dhps two locus point mutations, quadruple mutations were present in 7\% (6/80) of isolates and triple mutations in $27 \%(22 / 80)$. The majority $42 \%$ $(34 / 80)$ of isolates had double mutations, while $22 \%$ $(18 / 80)$ of isolates had single mutations. Notably, none of the isolates had quintuple mutations. Twenty-five percent $(20 / 80)$ of isolates with any of these mutations cleared parasitaemia after 24 hours of introduction of drug (Table 3). Ten different haplotypes were detected, of which, two were present in each site, two in Keonjhar and Ranchi, one (10\%) in Ranchi and West Garo Hills, while two (20\%) in Ranchi

Table 2 Prevalence of point mutation in dhfr and dhps gene in day 0 samples of patients enrolled for AS + SP therapeutic efficacy studies, central and eastern India, 2007 and 2010

\begin{tabular}{|c|c|c|c|c|c|c|c|}
\hline \multirow[b]{2}{*}{ Genes } & \multicolumn{3}{|c|}{ Keonjhar $(n=71)$} & \multicolumn{2}{|c|}{ Ranchi $(n=53)$} & \multicolumn{2}{|c|}{ WGH $(n=25)$} \\
\hline & Codons & $n \mathrm{M}$ & $\% \mathrm{M}$ & $\mathrm{n} \mathrm{M}$ & $\% M$ & $\mathrm{n} \mathrm{M}$ & $\% \mathrm{M}$ \\
\hline \multirow[t]{3}{*}{ dhfr } & C59R & 5938 & 64 & 5336 & 68 & 1818 & 100 \\
\hline & $\mathrm{S} 108 \mathrm{~N}$ & 6060 & 100 & 5050 & 100 & 1919 & 100 \\
\hline & I164L & 6020 & 33 & 5218 & 35 & 145 & 36 \\
\hline \multirow[t]{2}{*}{ dhps } & K540E & 2811 & 39 & 284 & 12 & 106 & 60 \\
\hline & A581G & 288 & 28 & 285 & 14 & 150 & 0 \\
\hline
\end{tabular}

Abbreviations: $W G H$, West Garo Hills; $n$, number; $M$, mutant. alone and three (30\%) in Keonjhar alone. Maximum numbers of haplotype were seen in Keonjhar (Table 4).

\section{Correlation of molecular markers with clinical outcomes}

Among the two treatment failures, molecular genotyping of isolates of day 0 and failure day revealed that in both cases isolates had double mutations in $d h f r(108+59)$ in day 0 , while failure day isolates had an additional mutation in dhps, one with 540, the other with 581 mutations.

Complete clearance of parasitaemia in less than 24 hours were observed in $78 \%(116 / 149)$ of patients, while $21 \%$ $(31 / 149)$ cleared in between 24 to 48 hours. Only $1 \%$ $(2 / 149)$ cleared in more than 48 hours. There was no statistically significant association between parasite clearance time and increased mutations in $d h f r$ and $d h p s$ $(P$ value $=1.24)$. However, among the isolates that cleared parasitaemia in more than 48 hours, all of them carried $108+59$ mutations. Isolates with $108+164+540$ cleared parasites between 24 to 48 hours.

\section{Discussion}

AS + SP remained efficacious for the treatment of $P$. falciparum across diverse sites in central and eastern India. Molecular genotyping of dhfr and dhps genes indicate the dominance of isolates with $d h f r$ double 
Table 3 Antifolate (dhfr and dhps) mutations, clinical outcome and parasite clearance time of patients enrolled for AS + SP treatment, central and eastern India, 2007 and 2010

\begin{tabular}{lllll}
\hline Type of mutation & $\mathbf{n}(\mathbf{8 0})$ & \multicolumn{2}{l}{$\mathbf{P C T}>\mathbf{2 4} \mathbf{h}$} & Outcome \\
\cline { 3 - 4 } & & $\mathbf{n}$ & $\mathbf{\%}$ & \\
\hline Quadruple & 6 & 2 & 34 & ACPR \\
Triple & 22 & 6 & 27 & ACPR \\
Double & 34 & 7 & 20 & ACPR \\
Single & 18 & 5 & 28 & ACPR \\
\hline
\end{tabular}

Abbreviations: $A C P R$, adequate clinical and parasitological response.

mutation and dhps wild type suggesting the ongoing development of antifolate resistance.

Despite the presence of mutations in $d h f r$ and dhps gene, AS + SP treatment remained successful. This may be due to several reasons: first, the action of artemisinin in combination therapy, which kills parasites rapidly and reduces SP drug pressure on the parasite, preserving the latter's efficacy; second, the rarity of $d h f r-d h p s$ quintuple mutations, which are virtually synonymous with SP treatment failure, in the population studied. However, it is likely that in the course of time such haplotypes may develop and spread in the face of sustained selection pressure; third, host immunity contributes to treatment efficacy and the study population was dominated by persons of tribal ethnicity living in highly endemic areas, who would have high immunity. The findings of this study were similar to those of Mishra et al. who reported AS + SP combination as a safe and effective treatment for uncomplicated falciparum malaria in India during 2009-2010 across 22 sites [14]. This study contributes 'baseline' data on antifolate resistance as the bulk of samples were collected in 2007 prior to the widespread scale-up of AS + SP.

SP is extensively used, widely available, inexpensive, and slowly eliminated from the body. These factors have promoted the emergence and spread of SP-resistant parasites. Mutations in $d h f r$ gene are related to pyrimethamine resistance and develop stepwise, starting with the mutation at codon S108N (Ser-Asn), followed by subsequent mutations at codon 59 (Cys-Arg), 51 (Asn-Ile) and 164. (Ile-Leu). In India, the most common dhfr mutation is S108N, followed by C59R, and N51I $[17,19,20]$. The results of this study showed a similar pattern with the exception of an absence of mutation in codon N51I. It was observed the I164L mutation associated with high levels of pyrimethamine resistance [21]. Previous studies in Assam, in north-east India and Odisha in eastern India, documented the dhfr triple mutant Asn108 + Ile51 + Arg59 associated with pyrimethamine resistance [17]. These combinations of mutations were not detected in the present study sites which are in nearby states. The $d h f r$ double mutations (S108N + C59R) were the most prevalent here similar to other reported results [22]. This study did not detect any quadruple mutations in dhfr such as those reported from the Andaman and Nicobar Islands by Ahmed [20] and Das et al. [23]. The success rate of dhps gene amplification was low compared to amplification of the $d h f r$ gene; however, isolates where it was successfully amplified were wild type. Other authors have also reported the dominance of wild type dhps genotype in India [14,17,22,]. The prevalence of dhps single mutation (K540E or A581G) and double mutations $(540+580)$ were low and triple mutant dhps alleles were not detected though reports exist, again, from the Andaman and Nicobar Islands [24].

Table 4 Prevalence of $d h f r / d h p s$ haplotype in day 0 samples of patients enrolled for AS + SP therapeutic efficacy studies, central and eastern India, 2007 and 2010

\begin{tabular}{|c|c|c|c|c|c|c|c|}
\hline \multirow[t]{3}{*}{ Mutations } & \multirow[t]{3}{*}{ Genotypes (dhfr/dhps) } & \multirow{2}{*}{\multicolumn{2}{|c|}{$\begin{array}{l}\text { Keonjhar } \\
(n=42)\end{array}$}} & \multirow{2}{*}{\multicolumn{2}{|c|}{$\begin{array}{l}\text { Ranchi } \\
(n=32)\end{array}$}} & \multirow{2}{*}{\multicolumn{2}{|c|}{$\begin{array}{l}\text { WGH } \\
(n=6)\end{array}$}} \\
\hline & & & & & & & \\
\hline & & $\mathbf{n}$ & $\%$ & $\mathbf{n}$ & $\%$ & $\mathbf{n}$ & $\%$ \\
\hline 4 & $\mathrm{~N}_{51} \mathbf{R}_{59} \mathbf{N}_{108} \mathrm{I}_{164} / \mathrm{S}_{436} \mathrm{~A}_{437} \mathbf{E}_{540} \mathbf{G}_{581} \mathrm{~A}_{613}$ & - & - & 2 & 6 & - & - \\
\hline 4 & $\mathrm{~N}_{51} \mathbf{R}_{59} \mathbf{N}_{108} \mathbf{L}_{164} / \mathrm{S}_{436} \mathrm{~A}_{437} \mathbf{E}_{540} \mathrm{~A}_{581} \mathrm{~A}_{613}$ & 2 & 4 & - & - & 2 & 33 \\
\hline 3 & $\mathrm{~N}_{51} \mathbf{R}_{59} \mathbf{N}_{108} \mathbf{L}_{164} / \mathrm{S}_{436} \mathrm{~A}_{437} \mathrm{~K}_{540} \mathrm{~A}_{581} \mathrm{~A}_{613}$ & 6 & 14 & 4 & 13 & - & - \\
\hline 3 & $\left.\mathrm{~N}_{51} \mathbf{R}_{59} \mathbf{N}_{108}\right|_{164} / \mathrm{S}_{436} \mathrm{~A}_{437} \mathbf{E}_{540} \mathrm{~A}_{581} \mathrm{~A}_{613}$ & 4 & 10 & 2 & 6 & 3 & 50 \\
\hline 3 & $\mathrm{~N}_{51} \mathrm{C}_{59} \mathbf{N}_{108} \mathbf{L}_{164} / \mathrm{S}_{436} \mathrm{~A}_{437} \mathbf{E}_{540} \mathrm{~A}_{581} \mathrm{~A}_{613}$ & 1 & 2 & - & - & - & - \\
\hline 3 & $\mathrm{~N}_{51} \mathbf{R}_{59} \mathbf{N}_{108} \mathrm{l}_{164} / \mathrm{S}_{436} \mathrm{~A}_{437} \mathrm{~K}_{540} \mathbf{G}_{581} \mathrm{~A}_{613}$ & - & - & 2 & 6 & - & - \\
\hline 2 & $\mathrm{~N}_{51} \mathbf{R}_{59} \mathbf{N}_{108} \mathrm{I}_{164} / \mathrm{S}_{436} \mathrm{~A}_{437} \mathrm{~K}_{540} \mathrm{~A}_{581} \mathrm{~A}_{613}$ & 12 & 29 & 13 & 41 & 1 & 17 \\
\hline 2 & $\mathrm{~N}_{51} \mathrm{C}_{59} \mathbf{N}_{108} \mathbf{L}_{164} / \mathrm{S}_{436} \mathrm{~A}_{437} / \mathrm{K}_{540} \mathrm{~A}_{581} \mathrm{~A}_{613}$ & 4 & 10 & - & - & - & - \\
\hline 2 & $\mathrm{~N}_{51} \mathrm{C}_{59} \mathbf{N}_{108} \mathrm{I}_{164} / \mathrm{S}_{436} \mathrm{~A}_{437} \mathbf{E}_{540} \mathrm{~A}_{581} \mathrm{~A}_{613}$ & 4 & 10 & - & - & - & - \\
\hline 1 & $\mathrm{~N}_{51} \mathrm{C}_{59} \mathbf{N}_{108} \mathrm{I}_{164} / \mathrm{S}_{436} \mathrm{~A}_{437} \mathrm{~K}_{540} \mathrm{~A}_{581} \mathrm{~A}_{613}$ & 9 & 21 & 9 & 28 & - & - \\
\hline
\end{tabular}


Regional variations of $d h f r$-dhps haplotypes were extensive, with some haplotypes common among Jharkhand, Odisha and West Garo Hills, while others were site specific. The highest number of haplotypes was present in Odisha, which contributes the highest proportion of the reported malaria burden in the country. Thus, high transmission generates higher diversity. In low-transmission areas in contrast, self-recombination leads to greater fixation of haplotypes. Ahmed et al. [17] described similar regional differences where more diverse genotypes were seen in the higher transmission states of Assam and Odisha. In addition to transmission, drug pressure varies across states. In low-transmission settings a greater proportion of infections are likely to be symptomatic, and since these areas also tend to be better developed, more cases will have access to care leading to high selection pressure. Anderson et al. [25] suggest resistance to SP appears to arise de novo much less frequently but spreads rapidly since gametocyte production is stimulated by this drug. High-level pyrimethamine-resistant alleles have emerged in independent foci from which they have rapidly spread to the nearby areas. In contrast, Vinayak et al. [26] found single origin for $d h f r$-resistant alleles in the Thai-Cambodia region, while $d h p s$-resistant alleles had multiple origins. Lumb et al. [27] reported several unique haplotypes among mutant dhps alleles and concluded that the dhps alleles in India have evolved from multiple genetic backgrounds.

Delayed parasite clearance time is the most important signal for artemisinin resistance [28]. The parasite clearance was rapid at all sites in this study. This rapid clearance of parasitaemia is suggestive of continued artemisinin effectiveness in India though better inference could be made with precise data on parasite clearance rates. No statistically significant association between parasite clearance time and increased mutations in $d h f r$ and dhps was observed, which was not surprising if the artemisinin component drives clearance. Since the treatment efficacy was high, it was not possible to correlate molecular results with subsequent treatment failure.

The present study had several limitations. Foremost was a follow-up of only 28 days. As the partner drug (SP) has a long half-life, extended follow-up for 42 days could have detected potential late treatment failures emerging with the elimination of residual drug levels. Second, only 25 patents were enrolled in West Garo Hills because enough eligible patients were not found at the recruitment site during the transmission season. Third, the lack of treatment failures restricted the ability to determine the relationship between molecular markers and AS + SP failure. Fourth, the parasite clearance time (PCT) was determined based on a daily blood smear. Finally, while three sites provided some geographic coverage, the results may not be generalizable across India given the size of the country and diversity of malaria ecotypes. The diversity of findings in $d h f r$ and $d h p s$ mutations alone suggests the need for routine monitoring especially in locations with a high prevalence of markers associated with anti-malarial drug resistance. One potential solution, which would minimize the need for expensive in vivo trials, is the targeting of such studies using molecular surveillance [29].

\section{Conclusion}

This study suggests that AS + SP remains effective for the treatment of uncomplicated falciparum malaria in central and eastern India despite the presence of mutations in the dhfr and dhps genes. Regular monitoring of the efficacy of AS + SP will help safeguard this combination treatment. Molecular studies of $d h f r$ and $d h p s$ would be helpful in detecting increased resistance against the partner drug SP and potentially targeting study sites to where treatment failure is likely to emerge.

\section{Abbreviations}

ACTs: Artemisinin combination therapy; AS + SP: Artesunate + sulphadoxinepyrimethamine; Pf: Plasmodium falciparum; dhfr: Dihydrofolate reductase; dhps: Dihydropteroate synthetase; PCT: Parasite clearance time.

\section{Competing interests}

The authors have declared that they have no competing interests.

\section{Authors' contributions}

PS: molecular studies and preparation of manuscript; NKS: review for molecular studies and manuscript; JR, NM and AA: critical review of manuscript; SKS and MKS: supervision and co-ordination of field work; BS: parasitological assessments; NV: development of protocol, quality control and review of manuscript. The authors have read and approved the final manuscript.

\section{Acknowledgements}

We are grateful to DG, ICMR for permission to undertake the study. PS is supported by a senior research fellowship from the Indian Council Medical Research. This manuscript has been approved by the NIMR publication committee. This paper bears the NIMR publication screening committee approval no. 007/2013.

\section{Author details}

${ }^{1}$ National Institute of Malaria Research, Sector 8, Dwarka, New Delhi 110077, India. ${ }^{2}$ School of life Sciences, Sambalpur University, Odisha 768019, India. ${ }^{3}$ National Institute of Malaria Research, Ranchi Field Unit, Ranchi, Jharkhand, India.

Received: 15 March 2013 Accepted: 7 July 2013

Published: 17 July 2013

\section{References}

1. Sharma VP: Battling the malaria iceberg with chloroquine in India. Malar $J$ 2007, 6:105.

2. Seghal P, Sharma M, Sharma S: Resistance to chloroquine in falciparum malaria in Assam state, India. J Commun Dis 1973, 5:175-180.

3. Barkakaty BN, Narasimham MV: Problem of anti malarial drug resistance in Plasmodium falciparum in Mizoram. Indian J Malariol 1992, 29:89-93.

4. Dua VK, Kar PK, Kumar S, Sharma VP: In vivo and In vitro sensitivity of Plasmodium falciparum to chloroquine at Indian Oil Corporation, Mathura, India. Indian J Malariol 1993, 30:29-35.

5. Giri A, Das MK: Response of $P$. falciparum to chloroquine in Car Nicobar Island. Indian J Malariol 1994, 31:27-30. 
6. Sathpathy SK, Jena RC, Sharma RS, Sharma RC: Status of Plasmodium falciparum resistance to chloroquine in Orissa. J Commun Dis 1997, 26:145-151.

7. Biswas S, Escalante A, Chaiyaroj S, Anglasekmine P, Lal AA: Prevalence of point mutation in the dihydrofolate reductase and dihydropteroate synthetase genes of Plasmodium falciparum isolates from India and Thailand: a molecular epidemiologic study. Trop Med Int Health 2000, 5:737-743.

8. WHO: Guidelines for the treatment of malaria. Geneva: World Health Organization; 2006.

9. Brown GM: The biosynthesis of folic acid II. Inhibition by sulfonamides. J Biol Chem 1962, 237:530-540.

10. Le Bras J, Durand R: The mechanism of resistance to antimalarial drugs in Plasmodium falciparum. Fundam Clin Pharmacol 2003, 17:147-153.

11. Dondrop AM, Nosten F, Yi P, Das D, Tarning APP, Lwin KM, Ariey F, Hanpithakpong W, Lee SJ, Ringwald P, Silamut K, Imwong M, Chotivanich K, Lim P, Herdman T, Sen Sam A, Yeung S, Singhasivanon P, Day NPJ, Lindegardh N, Socheat D, White NJ: Artemisinin resistance in Plasmodium falciparum malaria. N Engl J Med 2009, 361:455-467.

12. World Health Organization: Assessment and monitoring of antimalarial drug efficacy for the treatment of uncomplicated falciparum malaria. ; 2003. http://whqlibdoc.who.int/hq/2003/WHO_HTM_RBM_2003.50.pdf.

13. Vas D, Sangma BM, Dash AP: Persistent transmission of malaria in Garo Hills of Meghalaya bordering Bangladesh, north-east India. Malar J 2010, 9:263.

14. Mishra N, Singh JPN, Srivastava B, Arora U, Shah NK, Ghosh SK, Bhatt RM, Sharma SK, Das MK, Kumar A, Anvikar AR, Kaitholia K, Gupta R, Sonal JS, Dhariwal AC, Valecha N: Monitoring antimalarial drug resistance in India via sentinel sites: outcomes and risk factors for treatment failure, 20092010. Bull World Health Organ 2012, 90:895-904.

15. PMID: Revised National Drug Policy for treatment of malaria. J Indian Med Assoc 2010, 108:844-845. 21661462.

16. Snounou G, Zhu X, Siripoon N, Jarra W, Thaithong S, Brown KN, Viriyakosol $\mathrm{S}$ : Biased distribution of msp1 and msp2 allelic variants in Plasmodium falciparum populations in Thailand. Trans R Soc Trop Med Hyg 1999, 93:369-374.

17. Ahmed A, Bararia D, Vinayak S, Yameen M, Biswas S, Dev V, Kumar A, Ansari AM, Sharma YD: Plasmodium falciparum isolates in India exhibit a progressive increase in mutations associated with sulfadoxinepyrimethamine resistance. Antimicrob Agents Chemother 2004, 48:879-889.

18. World Health Organization: Methods for surveillance of antimalarial drug efficacy 2009; 2009. http://whqlibdoc.who.int/publications/2009/ 9789241597531_eng.pdf.

19. Sharma YD: Genetic alteration in drug resistance markers of Plasmodium falciparum. Indian J Med Res 2005, 121:13-22.

20. Ahmed A, Das MK, Dev V, Saifi MA, Khan W, Sharma YD: Quadruple mutations in dihydrofolate reductase of Plasmodium falciparum isolates from Car Nicobar Island. India. Antimicrob. Agents Chemother 2006, 50:1546-1549.

21. Andriantsoanirina V, Durand R, Pradines B, Baret E, Bouchier C, Ratsimbasoa A: In vitro susceptibility to pyrimethamine of DHFR I164L single mutant Plasmodium falciparum. Malar J 2011, 10:283.

22. Garg S, Saxena V, Kanchan S, Sharma P, Mahajan S, Kochar D, Das A: Novel point mutations in sulfadoxine resistance genes of Plasmodium falciparum from India. Acta Trop 2009, 110:75-79.

23. Das MK, Lumb V, Mittra P, Singh SS, Dash AP, Sharma YD: High chloroquine treatment failure rates and predominance of mutant genotypes associated with chloroquine and antifolate resistance among falciparum malaria patients from the island of Car Nicobar, India. J Antimicrob Chemother 2010, 65:1258-1261.

24. Lumb V, Das MK, Mittra P, Ahmed A, Kumar M, Kaur P, Dash AP, Singh SS, Sharma YD: Emergence of an unusual sulfadoxine-pyrimethamine resistance pattern and a novel K540N mutation in dihydropteroate synthetase in Plasmodium falciparum isolates obtained from Car Nicobar Island, India, after the 2004 Tsunami. J Infect Dis 2009, 199:1064-1073.

25. Anderson T: Mapping the spread of malaria drug resistance. PLOS Med 2009, 6:e1000054.
26. Vinayak S, Alam MT, Hayden TM, Mc Cllum AM, Sem R, Shah NK, Lim P, Muth S, Rogerrs WO, Fandeur T, Barnwell JW, Escalante AA, Wongsrichanalai C, Ariey F, Meshnick SR, Udhayakumar V: Origin and evolution of sulfadoxine resistant Plasmodium falciparum. PLoS Pathog 2010, 6:e1000830.

27. Lumb V, Das MK, Singh N, Dev V, Khan W, Sharma YD: Multiple origins of Plasmodium falciparum dihydropterote synthetase mutant alleles associated with sulfadoxine resistance in India. Antimicrob Agents Chemother 2011, 55:2813-2817.

28. Briena CO, Henricha PP, Passia N, David A, Fidocka B: Recent clinical and molecular insights into emerging artemisinin resistance in Plasmodium falciparum. Curr Opin Infect Dis 2011, 24:570-577.

29. Shah NK, Alker AP, Sem R, Susanti Al, Muth S, Maguire JD, Duong S, Ariey F, Meshnick SR, Wongsrichanalai C: Molecular surveillance for multidrugresistant Plasmodium falciparum, Cambodia. Emerg Infect Dis 2008, 14:1637-1640

doi:10.1186/1475-2875-12-247

Cite this article as: Srivastava et al:: A clinical and molecular study of artesunate + sulphadoxine-pyrimethamine in three districts of central and eastern India. Malaria Journal 2013 12:247.

\section{Submit your next manuscript to BioMed Central and take full advantage of:}

- Convenient online submission

- Thorough peer review

- No space constraints or color figure charges

- Immediate publication on acceptance

- Inclusion in PubMed, CAS, Scopus and Google Scholar

- Research which is freely available for redistribution

Submit your manuscript at www.biomedcentral.com/submit
C BioMed Central 